\title{
Dental Students' Perceived Preparedness to Treat Patients in Clinic After a Fixed Prosthodontics Course: Survey Results of a Case Study
}

\author{
Carlos Barrero, BDS, MS; Ibrahim Duqum, BDS, MS; Frank Petrola, BA
}

Abstract: Previous research regarding dental students has found modest predictive value in preclinical didactic course grades in predicting clinical performance, but systematic assessment of students' feedback on their perceived preparedness has received little attention as a preclinical assessment methodology. The aim of this study was to assess the perceptions of the dental students at one U.S. academic dental institution regarding their preparedness for clinical performance following the preclinical fixed prosthodontics course. Third- and fourth-year dental students participated in a survey about their perceived preparedness to diagnose and treat patients with fixed prosthodontics needs in the school's dental clinics. The respondents (79 out of 161 students, for a response rate of $49 \%$ ) rated each item on a five-point Likert scale. Responses about which preclinical procedures of the course prepared students the least and the best were consistent for the third- and fourth-year students. Less than $60 \%$ of all responding students felt prepared for planning complex cases and performing laboratory-related procedures. The findings of this study indicate that improvement is required in teaching students about laboratory procedures and problem-solving to adequately prepare them for clinical treatment of patients with fixed prosthodontics needs.

Dr. Barrero is Clinical Associate Professor, Department of Prosthodontics, University of North Carolina at Chapel Hill School of Dentistry; Dr. Duqum is Clinical Assistant Professor, Department of Prosthodontics, University of North Carolina at Chapel Hill School of Dentistry; and Mr. Petrola is Research Assistant, Department of Prosthodontics, University of North Carolina at Chapel Hill School of Dentistry. Direct correspondence to Dr. Carlos Barrero, Department of Prosthodontics, University of North Carolina at Chapel Hill School of Dentistry, 333 Brauer Hall, CB 7450, Chapel Hill, NC 27599; 919-537-3959; carlos_barrero@ dentistry.unc.edu.

Keywords: dental education, dental students, preclinical education, clinical performance, prosthodontics, fixed prosthodontics

Submitted for publication 5/6/14; accepted 9/16/14

$\mathrm{T}$ The ultimate goal of health professions education is to craft a program that integrates and implements the various domains of learning that ingrain competent practice. Over time, these programs should give students the means to achieve consistent, acceptable results in learning environments that mirror actual work settings. In pursuit of this result, dental schools must continually adjust their curricula, coursework, and contents in search of the best paradigm. ${ }^{1-3}$

Knowledge and skills are traditionally gained from the general environments of classroom, seminar, clinic, and peer interactions. Before entering the clinics, students' manual skill development begins with simulated bench-top procedures and techniques using mannequins - for example, when a student completes a fixed partial denture preparation on a typodont before transitioning into clinical care. Assessments are needed to determine if a student has integrated knowledge and/or skills sufficiently before transitioning to the next level of the curriculum. Educational innovations such as problem-based or case-based learning, patient simulations, blended learning, and service-learning have changed the ways we help students develop oral health care knowledge and skills. ${ }^{1-4}$ In a recent study of utilization of blended learning, not only did the students perform better with manual skills and conceptually, but they were more motivated and pleased with the new teaching technique. ${ }^{2}$ The movement towards a broader spectrum of teaching and learning methods in dental education underscores the importance of utilizing assessments that can consistently evaluate the impact and results of each new method.

In addition to evolving teaching techniques, changes in competency requirements as mandated by the Commission on Dental Accreditation (CODA) require continual assessment to ensure curriculum compliance. ${ }^{5}$ Dental schools must assess, adapt, and adjust their curricula to reflect changes to ensure students' preparedness to graduate. Previous commentary and expert opinion on assessment in 
health professions education indicate that we must evaluate not only students' recall and recognition of specific facts and demonstration of technical skills, but also their capacity to combine elements from different contexts and apply them to scenarios that require critical thinking and problem-solving., ${ }^{3,6-8}$ The continual assessment of curricular elements, both new and old, represents a critical component of successful education in the skills, knowledge, effective processes, and professional values that define the competent practice of dentistry. ${ }^{9-14}$ There have been many studies of assessment methodologies and curricular changes in dental education, ${ }^{15-25}$ although Maart and Bitzer found there was no or only modest predictive value in preclinical scores, grades, and performance for determining clinical performance. ${ }^{4}$

There are a variety of reasons why students may perform well in preclinical fixed prosthodontics exercises but not as well in clinic. Reasons for the discordance between these two assessment areas may be related to the type of curriculum in the dental school. In our institution, for example, a traditional curriculum has been used for many years with attempts to add, remove, or update areas or parts of it without truly changing the curricular framework. As a result, the current curriculum has become saturated and convoluted. A disadvantage of a traditional curriculum is a formal teaching style: teachers' lecturing students while the students are expected to absorb all the spoken information. ${ }^{26}$ This style fails to help students learn by means of fact finding and problemsolving. Time elapsed between material presented in preclinical courses and clinical experience, lack of faculty collaboration, faculty shortages, complexity of cases presented at a dental school, and the necessity to integrate multiple skills to treat a patient may be among the reasons for a disconnect between preclinical and clinical settings..$^{21,22}$

A study at Case Western Reserve University School of Dental Medicine shows the impact of an evolving curriculum to meet updated standards of education. ${ }^{25}$ Historically, this school used a traditional approach to education and the curriculum; however, the faculty and administrators felt a drastic change was needed to better prepare their future dentists. They redesigned their curriculum to implement a hybrid small-group learning environment. The hybrid approach still used traditional faculty instructional methods, but it was complemented with small-group learning, which enhanced development of critical thinking skills through problem-based learning (PBL) and integrated basic science and clinical science instruction. These changes enhanced the students' education and better prepare them for practice in the future.

The aim of our study was to assess the perceptions of dental students at one U.S. academic dental institution regarding their preparedness for clinical performance following the preclinical fixed prosthodontics course. The findings from this study will provide direction and guidance for further curricular integration and other changes.

\section{Methods}

This study was approved by the Biomedical Institutional Review Board at the University of North Carolina at Chapel Hill. For the study, we developed a Qualtrics online survey to assess the perceptions of third- and fourth-year dental students at the University of North Carolina at Chapel Hill regarding their preparedness to diagnose and treat patients with fixed prosthodontics needs. The survey consisted of 30 statements, which we based on the logical sequence of events for treatment planning and execution of simple fixed prosthodontics treatment. Items ranged from gathering of diagnostic data to cementation of restorations and recall of patients. The respondents indicated their agreement with each item, on a five-point Likert scale on which $1=$ strongly agree, $2=$ agree, $3=$ neutral, $4=$ disagree, and $5=$ strongly disagree. An email containing a link to the survey was sent to all third- and fourth-year students, with biweekly reminders for a period of six weeks.

After the respondents completed the survey, an exploratory factor analysis of the 30 items indicated that three factors were sufficient $(p=0.07)$. We assigned all items to one of the three factors if the factor score for that item was 0.25 or higher and if the difference between factor scores for that item was 0.10 or greater. Table 1 lists the items that loaded on each factor and the construct indicated by each factor. The standardized Cronbach coefficient alpha values were 0.81 for diagnosis and treatment planning, 0.71 for technical skills on execution of treatment, and 0.68 for laboratory procedures and problem-solving techniques, indicating good internal consistency and reliability of the construct. Average scores were calculated for each construct. Items and the average construct score were categorized as "effective" by combining 1 (strongly agree), 2 (agree), and 3 (neutral) or as "needs improvement" by combining 4 (disagree) and 5 (strongly disagree). 


\section{Table 1. Survey statements that correlated strongly with components of factor analysis}

\begin{tabular}{|c|c|c|}
\hline Component & $\begin{array}{l}\text { Statement } \\
\text { Number }\end{array}$ & Survey Statement \\
\hline \multirow{8}{*}{$\begin{array}{l}\text { Diagnosis } \\
\text { and treatment } \\
\text { planning }\end{array}$} & Q5 & $\begin{array}{l}\text { The information presented to you during fixed prosthodontics courses was helpful in deter- } \\
\text { mining sequencing and treatment needs of patients needing prosthodontic care. }\end{array}$ \\
\hline & Q6 & $\begin{array}{l}\text { The preclinical courses were helpful in providing sufficient information to recognize com- } \\
\text { plex cases requiring specialty referral or consultation. }\end{array}$ \\
\hline & Q7 & $\begin{array}{l}\text { Preclinical laboratory and lecture introduced me to the clinical procedures and requirements } \\
\text { that are located in the clinical manuals. }\end{array}$ \\
\hline & Q8 & $\begin{array}{l}\text { Preclinical fixed courses provided sufficient information to properly develop and sequence } \\
\text { in a orderly fashion a treatment plan. }\end{array}$ \\
\hline & Q18 & $\begin{array}{l}\text { Preclinical courses provided me with sufficient information to accurately complete a lab } \\
\text { prescription and communicate effectively with a laboratory technician. }\end{array}$ \\
\hline & Q22 & $\begin{array}{l}\text { Preclinical courses prepared me well in selecting the appropriate dental cement and com- } \\
\text { plete successfully permanent cementation procedure. }\end{array}$ \\
\hline & Q23 & $\begin{array}{l}\text { Preclinical courses provided me with sufficient information on how to repair (porcelain } \\
\text { fracture) and remove crowns. }\end{array}$ \\
\hline & Q24 & $\begin{array}{l}\text { Preclinical fixed prosthodontic courses assisted me in establishing recall appointments and } \\
\text { maintenance care for my patients. }\end{array}$ \\
\hline
\end{tabular}

Technical skills on execution of treatment procedures and problem-solving techniques
Q10 The preclinical diagnostic waxing exercise was helpful in preparing me to diagnose and treatment plan fixed prosthodontic patients.

Q12 Making a putty index before preparing the tooth, as taught in preclinical courses, is helpful in fabricating a provisional restoration and evaluating tooth reduction of crown preparations.

Q13 The tooth preparation sequence taught in preclinical is followed in clinic and supported by the faculty.

Q14 Preclinical laboratory and lecture instructions for direct provisional fabrication are followed in the clinic and supported by the faculty.

Q17 Preclinical fixed prosthodontic courses trained me well to make and evaluate final impressions for fixed restorations.

Q11 Duplicating the diagnostic wax-up and fabrication of a thermoplastic index as taught in the preclinical courses is very helpful in providing a guide for tooth reduction in clinic.

Q16 Preclinical fixed prosthodontic courses trained me well to place a retraction cord and manage soft tissue successfully.

Q25 The preclinical fixed prosthodontic courses provided adequate instruction for me to provide single crown therapy with minimal faculty chairside assistance.

Q9 The foundation and dowel core exercises on simulated vital and non vital (root canal treated) teeth were helpful in demonstrating clinical foundation scenarios.

Q19 The preclinical fixed prosthodontic experiences with dental laboratory soldering, glazing, and shade modification are helpful in providing clinical care for my prosthodontic clinic patients.

Q20 Information taught on color and shade selection in preclinical courses is helpful in selecting shade for my patient.

Q21 Preclinical courses prepared me well in delivering definitive restorations in fixed prosthodontic clinic.

\section{Results}

A total of 79 students out of the total 161 thirdand fourth-year students responded to the survey, for a response rate of $49 \%$. Of the 79 respondents, 39 were third-year students, and 40 were fourth-year students. In their responses, $66 \%$ of the students reported they were satisfied overall with the course, and between $24 \%$ and $91 \%$ considered their education on specific topics was effective in preparing them for clinical activities, by indicating they agreed or strongly agreed with the statements (Figure 1). The differences in percentages between third- and fourth-year students were less than $10 \%$, except for the items in domain 3 (laboratory procedures and 


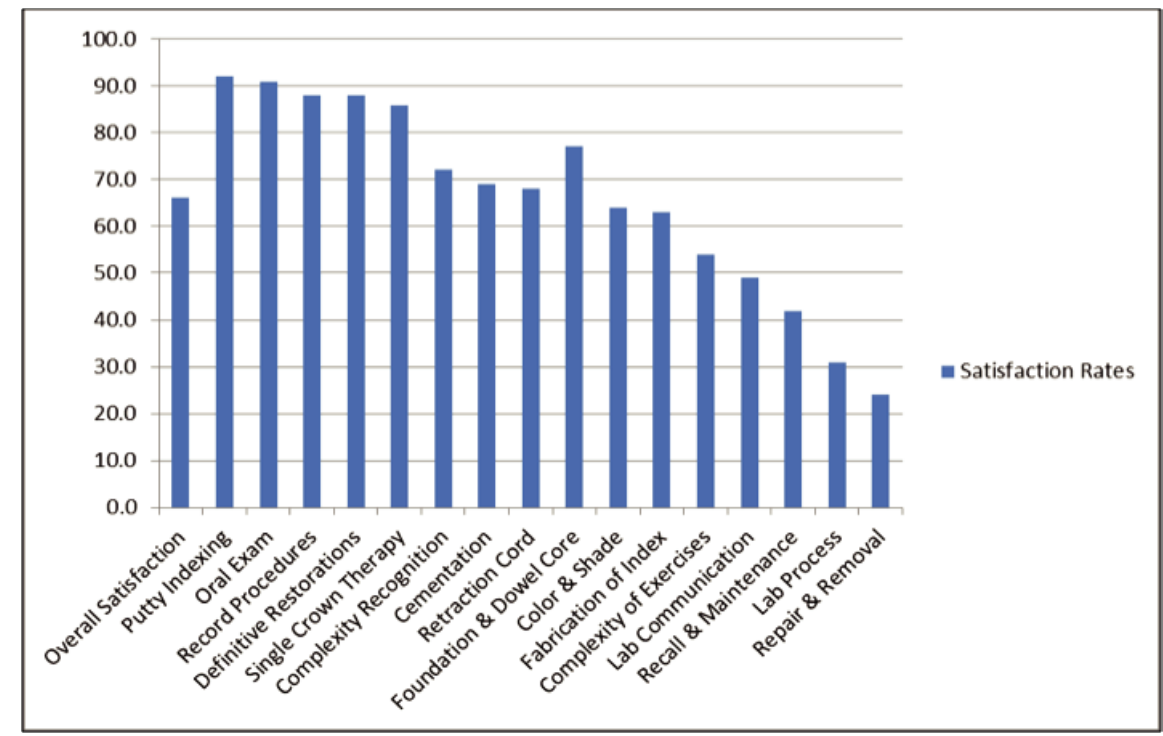

Figure 1. Percentage of students who rated each survey item effective in preparing them for clinical activities and their overall satisfaction with the course

Note: Satisfaction rates were determined by the percentages of students who indicated they agreed or strongly agreed with each item, on a five-point Likert scale on which 1=strongly agree, $2=$ agree, $3=$ neutral, $4=$ disagree, and 5=strongly disagree.

problem-solving techniques). Items that were rated as effective by over $80 \%$ of the students are listed in Table 2; those rated as effective by less than $60 \%$ are listed in Table 3; and those rated as effective by $60-80 \%$ are listed in Table 4.

The responding students perceived that the domain of diagnosis and treatment planning was less effective in preparing them for clinic (Figure 2) than the information presented in the other two domains. The rates of their perceived effectiveness in technical skills to execute treatment and laboratory procedures and problem-solving techniques were higher for the fourth-year students than the third-year students. This difference in perception could be explained by the increased exposure and experience the fourth-year students had had and their comfort level in the clinical setting when compared to the third-year students. Figure 3 presents the distribution of responses to items within domains; the largest differences between third- and fourth-year students were in laboratory procedures and problem-solving techniques.

\section{Discussion}

The majority of the total respondents found the preclinical fixed prosthodontics course to be effec- tive. Two-thirds of the respondents $(66 \%)$ agreed or strongly agreed with the statements and reported feeling that the preclinical fixed prosthodontics courses were helpful. It should be noted that since almost half of the respondents were third-year students, this could have skewed the responses since those students had less clinical experience than the fourth-year students and may not have encountered some of the survey items at the time of their participation in the study. It should also be noted that the survey was conducted while students were away from the school on their rotations. The intent was to give students a distance from the actual curricular setting. In retrospect, that timing may have negatively impacted the response rate, which could have resulted in sampling bias and is a potential limitation of the study.

The course components rated most highly by the respondents were the topics of putty indexing, oral examinations, record procedures, definitive restorations, and single crown therapy. These are the topics the course emphasizes for the benefit of the students' clinical experience. The high percentage of positive responses to this question could be related to the fact that, during the last few years, fixed prosthodontics course directors have included several hours of lectures of oral examination and diagnosis with patients who have fixed prosthodontics needs. On 
Table 2. Survey items rated as effective in preparing them for clinical activities by at least $80 \%$ of responding students

Survey Item

Topic

Effective \% Neutral \%

Making a putty index before preparing the tooth, as taught in preclinical courses, is helpful in fabricating a provisional restoration and evaluating tooth reduction of crown preparations.

The information presented to you during fixed prosthodontics courses was helpful when performing the intra- and extraoral examination of your patient/case.

Lectures and simulated procedures on preliminary impressions and occlusal records were helpful in obtaining adequate records for diagnosis and treatment planning of your prosthodontic patient/case.

Preclinical courses prepared me well in delivering definitive restorations in fixed prosthodontic clinic

The preclinical fixed prosthodontics courses provided adequate instruction for me to provide single crown therapy with minimal faculty chairside assistance.

\begin{tabular}{ccc} 
Topic & Effective $\%$ & Neutral $\%$ \\
\hline Putty indexing & $92 \%$ & $6 \%$ \\
Oral exam & $91 \%$ & $8 \%$ \\
Record procedures & $88 \%$ & $12 \%$ \\
Definitive restorations & $88 \%$ & $12 \%$ \\
Single crown therapy & $86 \%$ & $10 \%$
\end{tabular}

\section{Table 3. Survey items rated as effective in preparing them for clinical activities by less than $60 \%$ of responding students} Survey Item Topic Effective \% Neutral \%

The complexity of the fixed prosthodontic needs of my patients is congruent with the preclinical fixed prosthodontic exercises that I experienced in the preclinical fixed prosthodontic laboratory.

Preclinical courses provided me with sufficient information to accurately complete a lab prescription and communicate effectively with a laboratory technician.

Preclinical fixed prosthodontics courses assisted me in establishing recall appointments and maintenance care for my patients.

Complexity of exercises $\quad 54 \% \quad 26 \%$

Lab communication

$49 \%$

$20 \%$

The preclinical fixed prosthodontic experiences with dental laboratory soldering, glazing, and shade modification were helpful in providing clinical care for my prosthodontic clinic patients.

Preclinical courses provided me with sufficient information on how to repair (porcelain fracture) and remove crowns.

\begin{tabular}{|c|c|c|}
\hline Recall and maintenance & $42 \%$ & $35 \%$ \\
\hline Lab process & $31 \%$ & $43 \%$ \\
\hline Repair and removal & $24 \%$ & $27 \%$ \\
\hline
\end{tabular}

Table 4. Survey items rated as effective in preparing them for clinical activities by 60 to $80 \%$ of responding students

Survey Item

The preclinical courses were helpful in providing sufficient information to recognize complex cases requiring specialty referral or consultation.

Preclinical courses prepared me well in selecting the appropriate dental cement and completing successfully permanent cementation procedure.

Preclinical fixed prosthodontic courses trained me well to place a retraction cord and manage soft tissue successfully.

The foundation and dowel core exercises on simulated vital and non-vital (root canal treated) teeth were helpful in demonstrating clinical foundation scenarios.

Information taught on color and shade selection in preclinical courses is helpful in selecting shade for my patient.

Duplicating the diagnostic wax-up and fabrication of a thermoplastic index as taught in the preclinical courses is very helpful in providing a guide for tooth reduction in clinic.
Topic

Effective \% Neutral \%

\begin{tabular}{ccc} 
Topic & Effective $\%$ & Neutral \% \\
\hline Complexity recognition & $72 \%$ & $24 \%$ \\
Cementation & $69 \%$ & $19 \%$ \\
Retraction cord & $68 \%$ & $19 \%$ \\
Foundation and dowel core & $77 \%$ & $16 \%$ \\
Color and shade & $64 \%$ & $30 \%$ \\
Fabrication of index & $63 \%$ & $27 \%$ \\
& &
\end{tabular}




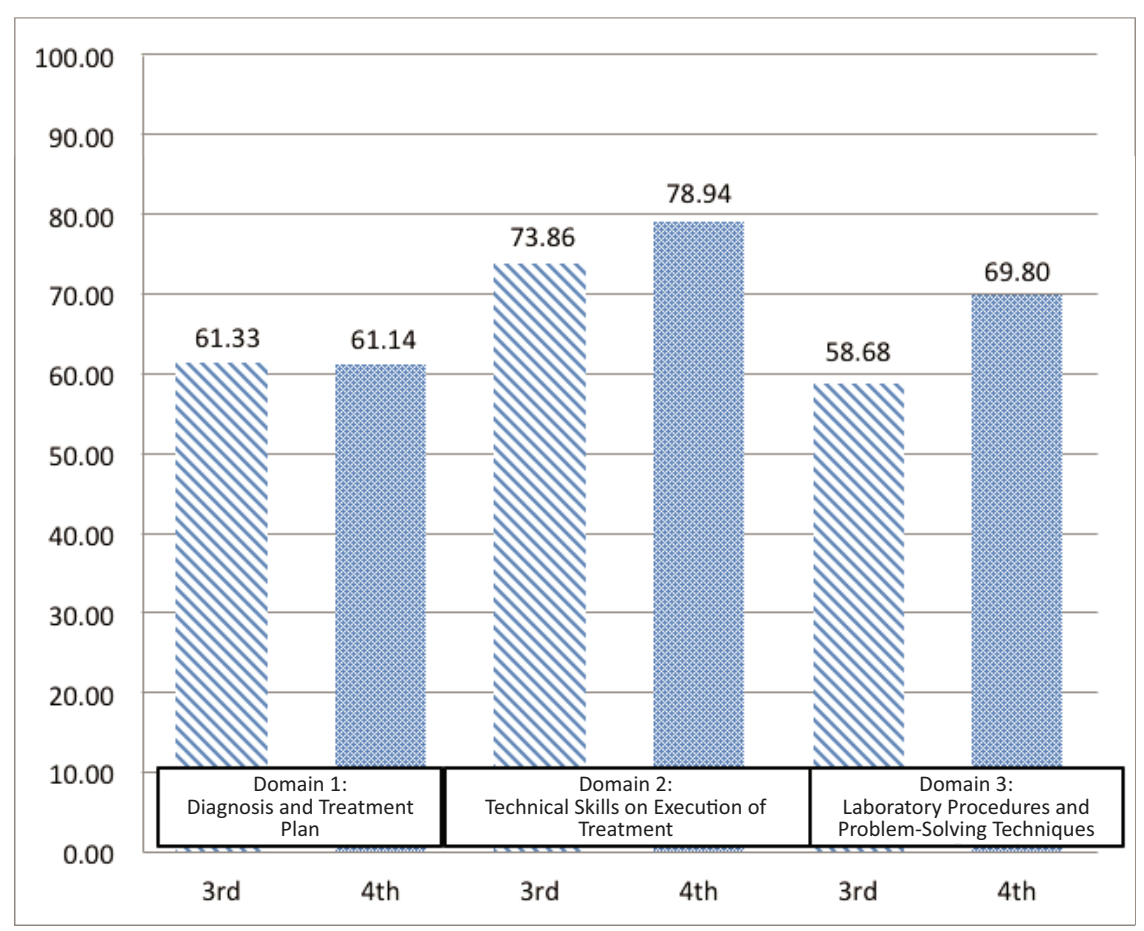

Figure 2. Factor analysis component effectiveness rates: percentages of third- and fourth-year students who rated each domain as effective in preparing them for clinic

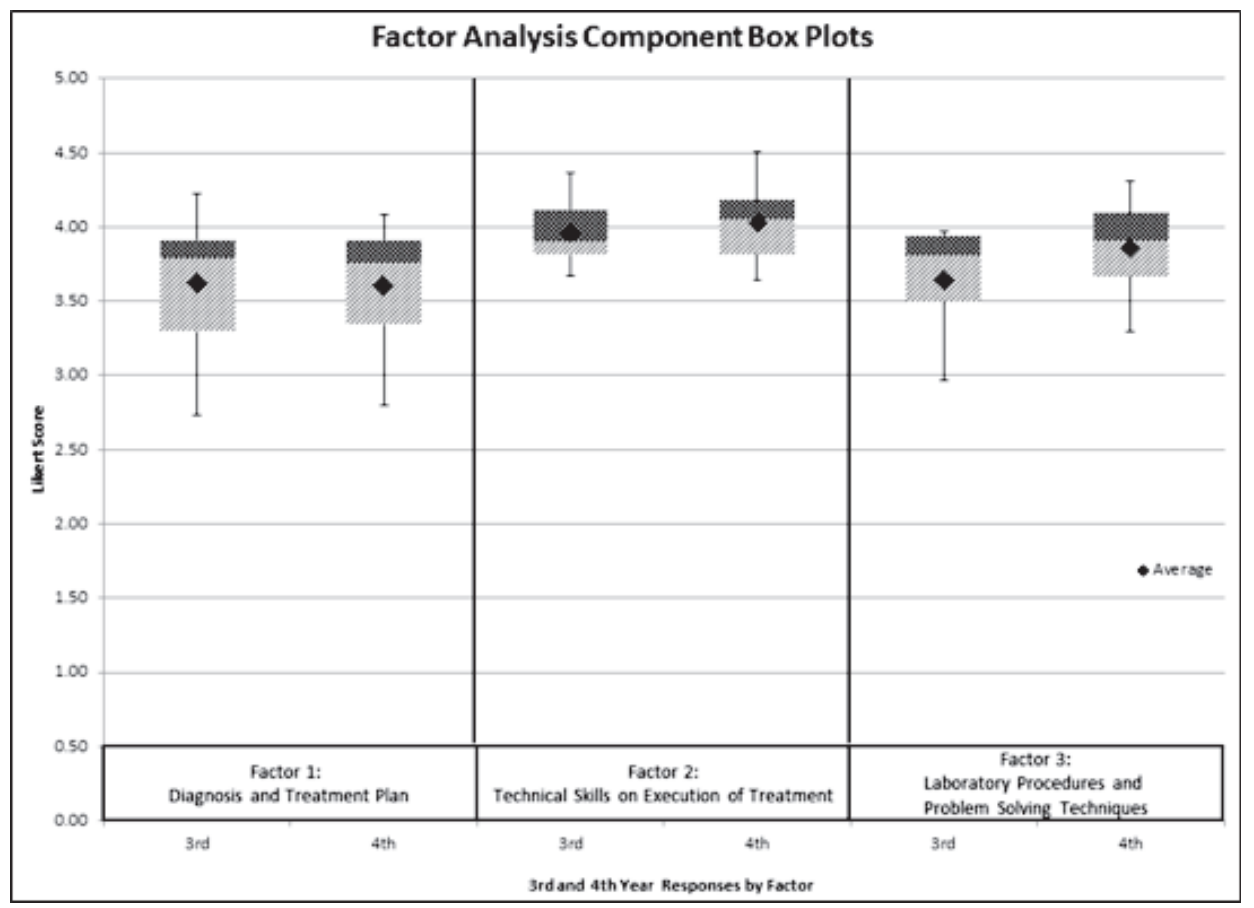

Figure 3. Results of factor analysis on survey results 
average, only $9.6 \%$ of the responses to these survey topics received a neutral response, indicating the students had clear opinions on these topics.

At the other end of the spectrum, the topics that scored below $60 \%$ in effectiveness were complexity of exercises, lab communication, recall and maintenance, lab process, and repair and removal. On average, their effectiveness rate was $40 \%$, with a minimum effectiveness rate of $24 \%$. It is clear that these are the areas in which the students need improvement to have a positive impact on their clinical experience. However, the average percentage of responses that were rated neutral for these topics was $30.2 \%$, with a minimum neutral response rate of $20 \%$. This unusually high percentage of respondents who answered neutral could indicate students who had not had clinical experience and could not render a definitive opinion.

Given that three of the five lowest-rated topics were less related to technical skill and were more lab-oriented or administrative in nature (lab communication, recall and maintenance, and lab process), the results indicate that these processes may have been oversimplified during preclinical instruction. Once in clinic, there could be a host of other factors that complicated an otherwise simple process. A key point garnered from these results is that preclinical education should not be limited to emphasizing clinical skills, but also ensuring that the students are comfortable with the administrative tasks and lab responsibilities that are intrinsic components of addressing patient needs. To see improvement in these areas, we recommend having written instructions available on the school's website for easy access for the students outside class lectures.

The factor analysis results revealed high levels of effectiveness in technical skills on execution of treatment by both the responding third- and fourthyear students $(73.86 \%$ and $78.94 \%$, respectively). This result indicates that students in both years felt that the preclinical course provides the means to help them develop the skills necessary to successfully treat their patients in clinic. The results for diagnosis and treatment planning received very similar effectiveness rates for both the responding third- and fourthyear students $(61.33 \%$ and $61.14 \%$, respectively). These effectiveness rates, while acceptable, show that the students need to have improved lessons in diagnosis and treatment planning.

The domain of laboratory procedures and problem-solving techniques showed the largest difference between the two classes; the third-year student ef- fectiveness rate was $58.68 \%$, while the fourth-year student effectiveness rate was $69.80 \%$. While the third-year effectiveness rate was much lower than the fourth-year rate, the average percentage of neutral responses for this domain was higher for the thirdyear students (30.05\%) than the fourth-year students $(22.43 \%)$. Again, the unusually high percentage of respondents who answered neutral could indicate students who had not had clinic experience and could not render a definitive opinion.

One suggestion to improve the preclinical fixed prosthodontic course is to incorporate more faculty lectures and demonstrations in the lab and add dental laboratory technicians in our clinical program to gradually reinforce, support, and supervise information that may be difficult to simulate in the preclinical program. In the past, we recall that a large number of U.S. dental schools had dental technicians in their predoctoral programs helping with the teaching mission of the school. Another method to remedy the factors with low effectiveness rates is by implementing a vertically integrated curriculum, which could especially resolve the low effectiveness rates in two course domains (diagnosis and treatment planning, and laboratory procedures and problem-solving techniques). By having preclinical students connected to higher level students in the clinic, the areas that are not receiving appropriate emphasis in class can be complemented by their peers' experiences in clinics and laboratories. Finally, the educational experience could be improved with the addition of such teaching methods as PBL (a recent study, for example, reported that students learned as much information and performed as well on exams and national tests using PBL as in traditional classroom learning ${ }^{23}$ ), blended learning (in which a student can access materials in a classroom setting, online, or in a laboratory setting ${ }^{2}$ ), flipped classroom learning (in which students learn at home in an online class or text reading and perform homework problems/ PBL scenarios in class with the instructor ${ }^{24}$ ), and/ or microburst learning (in which students have their usual class time in a semester, but also experience brief review lectures covering the same material in an upcoming year; www.microburstlearning.com).

\section{Conclusion}

In our study, the answers to questions regarding which procedures in preclinical fixed prosthodontics programs prepared students the least and the best 
were consistent. Diagnosis and treatment planning, foundation and post and core preparation, and cementation selection and procedures were selected by the fewest students as areas that best prepare students for clinic. These areas were also selected by the most students as areas that prepare students the least for clinic. These rankings suggest that improvement is needed in these areas to bring them up to par with the rest of the program. Faculty shortages, lack of dental technicians, and budget constraints would be easy scapegoats for the apparent shortfall in teaching the aspects of treatment planning and sequencing of treatment. We are making our results and suggestions available to course directors at our institution, so that courses may be updated to enhance the students' educational experience. While our research suggests there are weaknesses in the current system, further research is necessary, such as distributing another survey after some curricular changes have been made to determine if students' preparedness has been positively affected. However, despite its shortcomings, the current curriculum and system provide the most viable way of teaching motor skills and simulating dental practice.

\section{REFERENCES}

1. Office of Planning, Evaluation, and Policy Development. Evaluation of evidence-based practices in online learning: a meta-analysis and review of online learning studies. Washington, DC: U.S. Department of Education, 2010.

2. Maresca C, Barrero C, Duggan D, et al. Utilization of blended learning to teach preclinical endodontics. J Dent Educ 2014;78(8):1194-204.

3. Susarla SM, Medina-Martinez N, Howell TH, Karimbux NY. Problem-based learning: effects on standard outcomes. J Dent Educ 2003;67(9):1003-10.

4. Maart RD, Bitzer EM. Aligning clinical assessment with course elements in prosthodontic dentistry: a South African case. J Dent Educ 2013;77(9):1129-39.

5. Commission on Dental Accreditation. Accreditation standards for dental education programs. At: www.ada. org/sections/educationAndCareers/pdfs/predoc_2013.pdf. Accessed 4 Feb. 2014.

6. Triola MM, Friedman E, Cimino C, et al. Health information technology and the medical school curriculum. Am J Manag Care 2010;16(12 Suppl HIT):SP54-6.

7. Schultze-Mosgau S, Thorwarth WM, Grabenbauer GG, et al. The concept of a clinical round as a virtual, interactive web-based, e-learning model for interdisciplinary teaching. Int J Comput Dent 2004;7(3):253-62.

8. Mattheos N, Nattestad A, Schittek M, Attström R. A virtual classroom for undergraduate periodontology: a pilot study. Eur J Dent Educ 2001;5(4):139-47.

9. Peroz I, Beuche A, Peroz N. Randomized controlled trial comparing lecture versus self-studying by an online tool. Med Teach 2009;31(6):508-12.
10. Quinn F, Keogh P, McDonald A, Hussey D. A study comparing the effectiveness of conventional training and virtual reality simulation in the skills acquisition of junior dental students. Eur J Dent Educ 2003;7(4):164-9.

11. Obrez A, Briggs C, Buckman J, et al. Teaching clinically relevant dental anatomy in the dental curriculum: description and assessment of an innovative module. J Dent Educ 2011;75(6):797-804.

12. Curnier F. Teaching dentistry by means of virtual reality: the Geneva project. Int J Comput Dent 2010;13(3):251-63.

13. Kleinert HL, Sanders C, Mink J, et al. Improving student dentist competencies and perception of difficulty in delivering care to children with developmental disabilities using a virtual patient module. J Dent Educ 2007;71(2):279-86.

14. Welk A, Splieth Ch, Seyer D, et al. German dental faculty attitudes towards computer-assisted simulation systems correlated with personal and professional profiles. Eur J Dent Educ 2006;10(2):87-95.

15. Polyzois I, Claffey N, McDonald A, et al. Can evaluation of a dental procedure at the outset of learning predict later performance at the preclinical level? A pilot study. Eur J Dent Educ 2011;15(2):104-9.

16. Wierinck E, Puttemans V, van Steenberghe D, et al. Computer-assisted dental simulation as a predictor of preclinical operative dentistry performance. J Dent Educ 2011;75(9):1249-55.

17. Wierinck E, Puttemans V, van Steenberge D. Effect of tutorial input in addition to augmented feedback on manual dexterity training and its retention. Eur J Dent Educ 2006;10(1):24-31.

18. Albino JE, Young SK, Neumann LM, et al. Assessing dental students' competence: best practice recommendations in the performance assessment literature and investigation of current practices in predoctoral dental education. J Dent Educ 2008;72(12):1405-35.

19. Curtis DA, Lind SL, Dellinges M, et al. Dental students' self-assessment of preclinical examinations. J Dent Educ 2008;72(3):265-77.

20. Curtis DA, Lind SL, Brear S, Finzen FC. The correlation of student performance in preclinical and clinical prosthodontic assessments. J Dent Educ 2007;71(3):365-72.

21. Henzi D, Davis E, Jasinevicius R, Hendricson W. North American dental students' perspectives about their clinical education. J Dent Educ 2006;70(4):361-77.

22. DeBate RD, Cragun D, Severson HH, et al. Factors for increasing adoption of e-courses among dental and dental hygiene faculty members. J Dent Educ 2011;75(5):589-97.

23. Sukotjo C, Thammasitboon K, Howell H, Karimbux $\mathrm{N}$. The impact of targeted shortened preclinical exercises on student perceptions and outcomes. J Dent Educ 2007;71(8):1070-9.

24. McLaughlin JE, Roth MT, Glatt DM, et al. The flipped classroom: a course redesign to foster learning and engagement in a health professions school. Acad Med 2014;89(2):236-43.

25. Pyle MA, Goldberg JS. Engineering curriculum change at a private midwest school of dental medicine: a faculty innovation. J Dent Educ 2008;72(3):288-98.

26. Feld MJ, ed. Dental education at the crossroads: challenges and change. An Institute of Medicine report. Washington, DC: National Academies Press, 1995. 